\title{
Intentional Vocabulary Learning Using Digital Flashcards
}

\author{
Hsiu-Ting Hung ${ }^{1}$ \\ ${ }^{1}$ National Kaohsiung First University of Science and Technology, Kaohsiung, Taiwan, R.O.C. \\ Correspondence: Hsiu-Ting Hung, 1, University Road, Yanchao District, Kaohsiung, Taiwan, R.O.C. Tel: \\ 1-886-7-601-1000. E-mail: hhung@nkfust.edu.tw
}

Received: July 6, 2015 Accepted: September 12, 2015 Online Published: September 13, 2015

doi:10.5539/elt.v8n10p107 URL: http://dx.doi.org/10.5539/elt.v8n10p107

\begin{abstract}
As an attempt to follow through on the claims made by proponents of intentional vocabulary learning, the present study set out to examine whether and how digital flashcards can be incorporated into a university course to promote the vocabulary learning of English language learners. The overall research findings underscore the value of learning vocabulary with digital flashcards as an alternative to more conventional resources, and draw attention to the relative merits of embedding digital flashcards in collaborative learning tasks in classroom settings. This article then concludes by considering practical implications for supporting intentional vocabulary learning with the use of digital flashcards.
\end{abstract}

Keywords: intentional vocabulary learning, vocabulary learning techniques, digital flashcards, collaborative learning, English as a foreign language

\section{Introduction}

Methods of learning words with or without deliberate attempts are known as the intentional versus incidental learning in vocabulary research. While each approach has its merits and proponents, intentional vocabulary learning is of particular interest to this study. According to Elgort and Nation (2010), deliberate techniques, such as learning from vocabulary notebooks, word lists, and word cards, are useful approaches for achieving the acquisition of second language (L2) vocabulary effectively and efficiently. Based on a series of experimental studies, Elgort (2011) asserted that intentional learning of vocabulary is more efficient than incidental learning, as the latter often requires long-term and extensive exposure to linguistic input, and such naturalistic language learning conditions are not commonplace in English as a foreign language (EFL) contexts or other foreign language learning environments. In contrast, intentional learning of vocabulary speeds up learners' process of lexical development due to focused repetition or memorization strategies, which can be completed individually in a short period of time. It has also been argued that the retention rates of intentional vocabulary learning are generally higher than those obtained with incidental learning (Hustijn, 2003), suggesting that deliberate attempts to learning vocabulary are effective and worth the effort.

The general rationale for intentional vocabulary learning is grounded in Schmidt's (1990) noticing hypothesis, which states that noticing is the necessary condition for second language acquisition. As applied to lexical development, language learners must consciously notice L2 features in the input and pay deliberate attention to form-meaning connections of vocabulary items to optimize L2 learning. It is for this reason that vocabulary is commonly taught explicitly and directly in foreign language classrooms to compensate for the limited exposure and resources that may otherwise be available. However, Nation (2011) cautioned against over application of explicit vocabulary instruction with teacher-imposed vocabulary exercises. Among various vocabulary learning techniques, he particularly advocated that teachers should guide their students to make use of word cards in learner-centered ways. As he argued, "Well directed deliberate vocabulary learning using word cards is very effective and much more efficient than teaching and vocabulary exercises" (p. 536).

Word cards are a set of double-sided cards designed for direct learning of vocabulary that allow learners to practice form-to-meaning and meaning-to-form recall in repeated retrieval of L2 words, by flipping the front and back sides of the cards. Given how they are used, word cards are also called flashcards, and may vary in form, ranging from printed to digital versions. While word cards or flashcards have long been used in language classrooms, the recent 
rapid growth in educational technology has just aroused the interest of lexical researchers. However, the effects of digital flashcards on vocabulary acquisition and the pedagogical implications of this have yet to be comprehensively investigated.

As an attempt to follow through on the claims made by proponents of intentional vocabulary learning (e.g. Elgort, 2011; Hustijn, 2003; Nation, 2011), this article aims to provide a practical view of implementing digital flashcards to facilitate learners' vocabulary acquisition in EFL settings. Through a classroom-based experiment, this study aims to investigate how digital flashcards can be integrated into deliberate learning tasks to improve students' vocabulary learning outcomes and experiences.

\section{Previous Research on Intentional Vocabulary Learning}

Using word cards or word lists to deliberately learn lexical items is a common practice among L2 learners. At their simplest, these intentional vocabulary learning techniques differ in the medium that lexical forms and meanings are presented, either on a set of double-sided cards or a sheet of paper. In practice, learning vocabulary with word lists has a relatively long history, and it was especially popular at the time when the Grammar Translation method dominated language teaching. Numerous vocabulary researchers have stressed the value of list learning. For instance, Yamamoto (2014) investigated how Japanese EFL university students used word lists in their out-of-class vocabulary learning processes, and to what extent explicit list learning led to gains in vocabulary. The students reported adopting and combining various learning strategies along with their self-study of the vocabulary list, among which memorization and repetition were the most important ones. The students would look at, write down, and/or read aloud the words repeatedly to reinforce their rote learning of the vocabulary items. Furthermore, the students' learning outcomes were satisfactory, as they were found to increase both their receptive and productive vocabulary size. These results demonstrate that word lists are useful in helping learners to focus on form and meaning simultaneously for repeated retrieval.

Word cards can be viewed as a variation of word lists, and are believed to offer more flexibility in creating interactive vocabulary activities for classroom teaching or self-testing. Building on the benefits of list learning, a few recent studies have extended the implementation of word lists to word cards that come in various delivery forms, such as paper- and web-based flashcards. For example, Komachali and Khodareza (2012) investigated the effects of using paper-based flashcards on Iranian EFL pre-university students' vocabulary knowledge. The results indicated that the use of flashcards significantly helped the students' vocabulary growth, compared to traditional vocabulary instruction without such aids.

Along the same line of promoting deliberate learning techniques, some vocabulary researchers have further compared the effects of learning with word lists and cards among EFL learners. Spiri (2008) adopted a free online flashcard tool, WordChamp, in a comparison study of Japanese university students drilling with digital flashcards versus printed word lists. As expected, the students who studied vocabulary on WordChamp outperformed those who studied with the word lists, while both of the learning techniques assisted the students in acquiring vocabulary. In another study that compared Japanese junior high school students' English vocabulary learning with word lists, word cards, and computer drills, Nakata (2008) found that the computer group achieved the highest retention rates, followed by the paper-based word card group and then the word list group. Based on these two empirical studies, flashcards appear to be more effective than word list, regardless of their delivery form.

It is also important to note that, in the literature reviewed above, the word cards or lists were mostly provided by the teacher for use by individuals in out-of-class or self-study contexts. Little research has been conducted on learner-generated word cards or lists, and on their possible applications in collaborative learning activities in classroom settings. Since intentional learning techniques are claimed to enhance direct teaching of vocabulary (Nation, 2011), and also encourage learner autonomy (Laufer, Meara, \& Nation, 2005), it is worthwhile to explore optimal ways in which such techniques can be integrated into vocabulary instruction and placed in the curriculum context. To address these limitations in the literature and respond to the current trends of technology enhanced language learning, this article thus focuses the discussion on the use of digital flashcards as an intentional vocabulary learning technique.

\section{Method}

\subsection{Setting and Participants}

This research was conducted at a public university in Taiwan, where students learn English as a foreign language. All the participants $(\mathrm{N}=75)$ were drawn from three intact classes of first-year English majors, averaging 25 
students per class. The students' ages ranged from 18 to 20 years. Based on their placement test scores, the majority of the students were intermediate level learners of English, while a small number of them were at the lower-intermediate level. They all enrolled in a required language course that was designed to develop students' English proficiency in all four skills, while also expanding their vocabulary knowledge. In the course under investigation, the students met three hours per week in a multimedia classroom, which was equipped with an individual desktop computer for each seat.

\subsection{Digital Flashcard Implementation}

Study Stack (http://www.studystack.com) is a free website that allows users to create their own flashcards for any subject. It is also recommended as one of the most popular and useful digital flashcard tools among high school and university students in the United States (Green \& Bailey, 2010). For this reason, it was chosen as the vocabulary learning tool for the purpose of this work. Study Stack offers students a wide range of study options to review information in the way that best suits their needs. One feature that makes Study Stack stand out from other flashcard tools is its affordances that allow students to automatically generate and customize various study activities and learning materials based on user input. In other words, the learner-generated flashcards on Study Stack can be practiced online in various game-based learning activities (e.g. Crossword and Hangman), or be printed out in different layout options to mimic traditional materials, such as word cards, word lists, and quizzes.

In this course, Study Stack was implemented as an intentional vocabulary learning tool for use in a vocabulary learning task, which required the students to choose at least five words from each weekly lesson to create their own digital flashcards for vocabulary learning. A 30-minute self-study session was set aside for the students to log into their personal accounts of Study Stack for task completion on a weekly basis for a duration of four weeks. The flashcard content should contain aspects of word knowledge, with the form and part of speech of each vocabulary item on one side of a flashcard, and its meaning on the other (i.e. L1 translation and L2 usage in the form of collocations or sentences). The completion of this vocabulary learning task accounted for 20 percent of the course grade. The students were also encouraged to practice their digital flashcards as a means to review the course content out of class.

\subsection{Research Design and Procedure}

This study involved three instructional conditions that were defined by varying task designs of flashcard use during the prescribed self-study sessions in class. These included 1) A self-practice format: The participants created five flashcards on their own and studied the material by themselves. 2) A pair-exchange format: The participants created five flashcards individually and took turns to exchange and study the flashcards with different peers, based on the instructor's random pairing assignments. 3) A group-based format: The participants first made five flashcards on an individual basis, and then collaboratively decided on ten useful words to be included in their group-based flashcards for later practice and review.

The length of the study was nine weeks. In weeks $1-2$, the participants were introduced to intentional learning techniques and took part in a series of vocabulary exercises to help them improve their study skills, followed by a workshop on Study Stack. In week 3, the participants took a 100-item translation test as a pre-test to assess their prior knowledge of the possible target words chosen from the four course lessons. To ensure that the participants started the study without prior knowledge of the target items, only the items that were unknown to all of them were considered as the final target words to be included in the post-test. The results of the pre-test led to the inclusion of 20 target words for the post-test. During the four-week implementation of vocabulary learning task (weeks 4-7), the three groups were randomly assigned to three different instructional conditions, as mentioned above. In week 8 , an attitudinal questionnaire based on Davis' (1989) Technology Acceptance Model (TAM) was administered to all the participants in class. The questionnaire consisted of nine five-point Likert scale items (where 1 represents strongly disagree and 5 indicates strongly agree) that were evenly devoted to three sub-scales, including perceived usefulness, perceived ease of use, and intention to use. It was used to survey the students' attitudes, particularly their acceptance of digital flashcards for vocabulary learning. Lastly, in week 9 , the participants were assessed in their retention of the 20 target words with a timed recall quiz that asked them to translate the target words from $\mathrm{L} 1$ to L2. This assessment served as a post-test of the study.

\section{Results}

The gathered data, including the vocabulary test scores and attitudinal questionnaire results, was examined using one-way ANOVA and post-hoc Tukey tests to establish the potential of digital flashcards to afford a variety of 
vocabulary learning tasks, and determine which task design led to better learning outcomes.

Table 1 presents a comparison of the statistical results for the three groups' vocabulary learning performance, as influenced by varying formats of learning tasks. The results indicated that the students who used digital flashcards to learn vocabulary collaboratively in small groups outperformed those in the other two experimental conditions in the post-test (group-based $>$ peer-exchange $>$ self-practice; $\mathrm{F}=15.981 ; \mathrm{p}<.001$ ), with no significant group differences found in the pre-test $(\mathrm{F}=.131 ; \mathrm{p}=.878)$.

Table 1. Comparison of group differences based on the vocabulary post-test scores

\begin{tabular}{lllllll}
\hline Groups & $\mathrm{N}$ & $\mathrm{M}$ & $\mathrm{SD}$ & $\mathrm{F}$ & $\mathrm{p}$ & Post-hoc Tukey \\
\hline (a) Self-practice & 25 & 81.40 & 6.04 & 15.981 & $.000^{*}$ & (c) $>$ (b)* \\
(b) Peer-exchange & 26 & 85.15 & 6.68 & & & (c) $>(\mathrm{a})^{*}$ \\
(c) Group-based & 24 & 91.88 & 6.73 & & & (b) $>(\mathrm{a})^{*}$ \\
\hline
\end{tabular}

Significance $* p<.05$.

In the analyses of the participants' attitudes toward the use of flashcards, not only did the group-based format lead to higher means than the other two (see Table 2), but the statistical results also demonstrate a consistently significant effect $(\mathrm{p}<.001)$ in each of the three TAM sub-scales of the attitudinal questionnaire (usefulness: $\mathrm{F}=$ 42.767; ease of use: $\mathrm{F}=26.549$; intention to use: $\mathrm{F}=54.865$ ).

Table 2. Descriptive statistics for the results of the attitudinal questionnaire by subscales

\begin{tabular}{|c|c|c|c|c|c|c|}
\hline \multirow{2}{*}{ Subscales (Maximum) } & \multicolumn{2}{|c|}{ Self-Practice $(\mathrm{N}=25)$} & \multicolumn{2}{|c|}{ Peer-Exchange $(\mathrm{N}=26)$} & \multicolumn{2}{|c|}{ Group-Based $(\mathrm{N}=24)$} \\
\hline & $\mathrm{M}$ & SD & $\mathrm{M}$ & SD & $\mathrm{M}$ & SD \\
\hline Usefulness (15) & 10.80 & 1.71 & 13.27 & 1.15 & 14.17 & 1.01 \\
\hline Ease of Use (15) & 11.00 & 1.87 & 13.35 & 0.94 & 13.58 & 1.18 \\
\hline Intention to Use (15) & 9.56 & 1.47 & 12.65 & 1.16 & 13.38 & 1.44 \\
\hline
\end{tabular}

A further analysis was conducted to assess the overall results of the TAM-based attitudinal questionnaire, using one-way ANOVA and post-hoc Tukey tests. As shown in Table 3, the students learning with the group-based format had a significantly higher level of acceptance about the vocabulary learning task than seen with the other two groups (group-based $>$ peer-exchange $>$ self-practice; $\mathrm{F}=118.9400 ; \mathrm{p}<.001$ ).

Table 3. Comparison of group differences based on the attitudinal questionnaire as a whole

\begin{tabular}{lllllll}
\hline Groups & N & Mean & SD & F & p & Post-hoc Tukey \\
\hline (a) Self-practice & 25 & 31.36 & 3.01 & 118.400 & $.000^{*}$ & (c) $>(\text { b })^{*}$ \\
(b) Peer-exchange & 26 & 39.27 & 1.97 & & & (c) $>(\text { a })^{*}$ \\
(c) Group-based & 24 & 41.13 & 1.99 & & & (b) $>(a)^{*}$ \\
\hline
\end{tabular}

Significance ${ }^{*} p<.05$.

Note: The maximum value of the 9-item 5-point Likert scale attitudinal questionnaire is 45.

In a broader sense, engaging students in collaborative learning tasks (in this case, the group-based and peer-exchange formats of task design) led to better learning outcomes, with respect to vocabulary gains and TAM-related attitudes, than having them study on their own individually. 


\section{Discussion and Implications}

This study set out to examine whether and how digital flashcards can be incorporated into a university course to promote the vocabulary learning of Taiwanese EFL learners. The findings of this research are congruent with those of previous studies (e.g. Nakata, 2008; Spiri, 2008), which suggests that the use of digital flashcards has potential to help learners enhance their vocabulary learning performance and elicit more favorable perceptions of intentional vocabulary learning. Notably, while former studies mostly investigated learners' flashcard use in out-of-class settings, the positive results observed in the present study extend their application to classroom use. Furthermore, the results of this study support the integrated use of digital flashcards in classroom-based tasks, with the small group design being superior to the pair and individual ones. These results also echo the trend for computer-supported collaborative learning (CSCL), which maintains that the use of computers and technologies creates a fostering environment that supports learning collaboratively rather than individually, with more satisfying learning outcomes (Stahl, Koschmann, \& Suthers, 2006).

The findings of the current study have practical implications for supporting intentional vocabulary learning with the use of digital flashcards. As in other studies, this research has shown that flashcard use allows for the act of retrieving information from memory, known as the testing effect (Roediger \& Karpicke, 2006; Karpicke \& Roediger, 2007). Instructors may thus advise students to use flashcards for self-testing or repeated retrieval of words, and students should be made aware of the robust benefits of using flashcards to learn vocabulary deliberately. More importantly, students should be educated about the effective use of flashcards (e.g. the amount and timing of practice), and this can be implemented through explicit strategy instruction in regular language courses or additional study skills workshops targeting first-semester freshmen.

A unique aspect of the present study is the collaborative learning potential of flashcard use. This research has demonstrated that while learning vocabulary with flashcards is considered more of an individual task, this intentional learning technique can be repurposed for collaborative learning tasks, with a sound instructional design, to allow for better peer support. Likewise, Newton (2001) put forward various design options for vocabulary learning techniques that promote collaborative learning, among which making flashcards is recommended as one practical approach. From the CSCL perspective, instructors may incorporate digital flashcard tools to have students work collaboratively and expose them to the interactive use of vocabulary, such as co-constructing vocabulary flashcards, testing each other on new words, and negotiating word meanings in communication. Ideally, the proposed technique of learning vocabulary deliberately with digital flashcards can and should be used to provide collaborative learning opportunities for lexical development in and out of class.

\section{Conclusion}

The overall findings of this study underscore the value of learning vocabulary with digital flashcards as an alternative to more conventional resources, and draw attention to the relative merits of embedding digital flashcards in collaborative learning tasks in classroom settings. This study, however, is limited in documenting the process and quality of students' actual use of digital flashcards for vocabulary learning. Future research may conduct more in-depth analyses on these aspects, using a qualitative method. Large-scale survey studies could also help to reveal students' perceptions of why and how they implement digital flashcards for individual or collaborative study.

\section{Acknowledgements}

This study was sponsored by the Ministry of Science and Technology (MOST) of Taiwan, R. O. C. under the grant MOST-104-2511-S-327-001.

\section{References}

Davis, F. D. (1989). Perceived usefulness, perceived ease of use, and user acceptance of information technology. MIS Quarterly, 13(3), 319-340. http://dx.doi.org/10.2307/249008

Elgort, I. (2011). Deliberate learning and vocabulary acquisition in a second language. Language Learning, 61(2), 367-413. http://dx.doi.org/10.1111/j.1467-9922.2010.00613.x

Elgort, I., \& Nation, P. (2010). Vocabulary learning in a second language: Familiar answers to new questions. In P. Seedhouse, S. Walsh, \& C. Jenks (Eds.), Conceptualizing Learning in Applied Linguistics (pp. 89-104). New York: Palgrave Macmillan.

Green, T., \& Bailey, B. (2010). Digital flashcard tools. TechTrends, 54(4), 16-17. 
http://dx.doi.org/10.1007/s11528-010-0415-2

Hulstijn, J. H. (2003). Incidental and intentional learning. In C. J. Doughty, \& M. H. Long (Eds.), The Handbook of Second Language Acquisition (pp. 349-381). Malden, MA: Blackwell. http://dx.doi.org/10.1002/9780470756492.ch12

Karpicke, J. D., \& Roediger, H. L. (2007). Repeated retrieval during learning is the key to long-term retention. Journal of Memory and Language, 57(2), 151-162. http://dx.doi.org/10.1016/j.jml.2006.09.004

Komachali, M. E., \& Khodareza, M. (2012). The effect of using vocabulary flash card on Iranian pre-university students' vocabulary knowledge. International Education Studies, 5(3), 134-147. http://dx.doi.org/10.5539/ies.v5n3p134

Laufer, B., Meara, P., \& Nation, P. (2005). Ten best ideas for teaching vocabulary. The Language Teacher, 29(7), $3-6$.

Nakata, T. (2008). English vocabulary learning with word lists, word cards and computers: Implications from cognitive psychology research for optimal spaced learning. ReCALL, 20(1), 3-20. http://dx.doi.org/10.1017/S0958344008000219

Nation, I. S. P. (2011). Research into practice: Vocabulary. Language Teaching, 44(4), 529-539. http://dx.doi.org/10.1017/S0261444811000267

Newton, J. (2001). Options for vocabulary learning through communicative tasks. ELT Journal, 55(1), 30-37. http://dx.doi.org/10.1093/elt/55.1.30

Roediger, H. L., \& Karpicke, J. D. (2006). Test-enhanced learning: Taking memory tests improves long-term retention. Psychological Science, 17(3), 249-255. http://dx.doi.org/10.1111/j.1467-9280.2006.01693.x

Schmidt, R. (1990). The role of consciousness in second language learning. Applied Linguistics, 11(2), 129-158. $\mathrm{http}: / / \mathrm{dx}$. doi.org/10.1093/applin/11.2.129

Spiri, J. (2008). Online study of frequency list vocabulary with the WordChamp website. Reflections on English Language Teaching, 7(1), 21-36.

Stahl, G., Koschmann, T., \& Suthers, D. (2006). Computer-supported collaborative learning: A historical perspective. In R. K. Sawyer (Ed.), Cambridge Handbook of the Learning Sciences (pp. 406-427). Cambridge, UK: Cambridge University Press. http://dx.doi.org/10.1007/s11412-006-9004-y

Yamamoto, Y. (2014). Multidimensional vocabulary acquisition through deliberate vocabulary list learning. System, 42(1), 232-243. http://dx.doi.org/10.1016/j.system.2013.12.005

\section{Copyrights}

Copyright for this article is retained by the author(s), with first publication rights granted to the journal.

This is an open-access article distributed under the terms and conditions of the Creative Commons Attribution license (http://creativecommons.org/licenses/by/3.0/). 